\title{
Clinical spectrum and causes of abnormal uterine bleeding in reproductive age according to two FIGO systems
}

\author{
Preeti Bala Singh, Roli Purwar, Ratna Priya Mall
}

Corresponding author: Dr. Roli Purwar, Senior Resident, Department of Obstetrics and Gynaecology, AIIMS, Gorakhpur, Uttar Pradesh, India; Email : purwarroli@gmail.com

Distributed under Attribution-Non Commercial - Share Alike 4.0 International (CC BY-NC-SA 4.0)

\begin{abstract}
Objectives: To analyse various causes of abnormal bleeding and their bleeding patterns in accordance with FIGO classification system in reproductive age women. Materials and methods: This was a cross-sectional, retrospective study done at All India Institute of Medical Sciences, Gorakhpur. Total of 116 women aged 15 to 55 years with chronic AUB between October 2019 and March 2020 were evaluated. Results: Most patients of AUB were in the age group between 30-39 years and 40-49 years (31.8\%), structural cause accounts for $32.6 \%$ and non structural cause accounts for $67.4 \%$ of cases. AUB-O i.e. ovulatory dysfunction (OD) was the commonest (non structural) finding in $55.2 \%$ women, followed by AUB-L i.e. leiomyoma (structural) in $18.6 \%$ of women. In adolescent, all cases (100\%) and in younger age group, $91.4 \%$ cases were due to OD. Most cases of AUB-O were due to anovulation (33.8\%) and PCOS (27.9\%). Most common age of presentation in AUB-L was $40-49$ years $(35.1 \%)$. Irregular cycle $(44.1 \%)$ and infrequent cycle (33.8\%) was most common bleeding pattern with AUB-O. AUB-L and AUB-A (adenomyosis) most commonly presented with heavy menstrual bleeding (HMB) i.e $86.9 \%$ and $66.7 \%$ of cases. AUB-P (polyp) presented with HMB (40\%) and intermenstrual bleeding (20\%). Conclusion: Non structural causes were the most common cause and AUB-O was the commonest cause occupying more than half of cases. Most common menstruation pattern in AUB -O was irregular cycles and in AUB-L it was HMB.
\end{abstract}

Keywords: Abnormal uterine bleeding, bleeding pattern in reproductive age group women, FIGO system, PALM COIEN classification.

Abnormal uterine bleeding (AUB) is defined as any type of bleeding in which the amount, duration, frequency and cyclicity is abnormal for a patient. ${ }^{1}$ It is very common symptom and it is seen in $15-20 \%$ of patient from the commencement of menarche to menopause. ${ }^{2}$ Over all prevalence of AUB varies in different population fluctuating between $10 \%$ and $30 \%,{ }^{3,4}$ For treatment of AUB, it is very important to know the aetiology of AUB. The International Federation of Gynaecology and Obstetrics (FIGO) initially published the consensus on the terms and definitions of normal and abnormal uterine bleeding in 2007, further in 2011, a new terminology and definitions and "Classification of causes of AUB in the reproductive years, the PALMCOEIN system" was introduced. Recommendations again updated in 2018 with certain minor changes. PALM-COIEN denotes AUB associated with polyp (AUB-P), adenomyosis (AUB-A), leiomyoma (AUB-L), malignancy and hyperplasia (AUB-M), coagulopathy (AUB-C), ovulatory dysfunction (AUB-O), endometrial (AUB-E), and iatrogenic and not otherwise classified (AUB-N). The "PALM" classification is structural and can be seen visually i.e. through (imaging and/or histopathological tests), whereas the "COEIN" classification is non-structural. ${ }^{5}$

Diagnosis of AUB depends upon comprehensive medical history, blood tests, imaging and histopathology. Bleeding pattern style forms the clinical basis for diagnosis of different types of AUB. Some standard menstrual index parameters are used to define bleeding pattern which are

Received: $18^{\text {th }}$ November 2020, Peer review completed: $29^{\text {th }}$ January 2021, Accepted: $5^{\text {th }}$ February 2021.

Singh PB, Purwar R, Mall RP. Clinical spectrum and causes of abnormal uterine bleeding in reproductive age according to two FIGO systems. The New Indian Journal of OBGYN. 2021; 8(1): 105-11. 
The New Indian Journal of OBGYN. 2021 (July-December);8(1)

frequency, duration, regularity, volume and intermenstrual bleeding. ${ }^{5}$

This study provides the prevalence of AUB, according to PALM - COIEN classification in Indian women and analysis of various causes and their bleeding patterns in accordance with FIGO classification system.

\section{Materials and methods}

This retrospective observational study was conducted in patients with chronic AUB presented to gynaecological OPD at All India Institute of Medical Sciences, Gorakhpur over last 6 months i.e. between October 2019 to March 2020. All the data were collected from departmental records and institutional computerised patient management system and was entered in carefully structured performa. Ethical clearance was taken from institute's ethical committee and study was ethically conducted in accordance with declaration of Helinski. All patients with any type of menstrual complaints were looked for and only those patients meeting the inclusion criteria were enrolled in the study and women with any of the exclusion criteria were excluded from evaluation.

Inclusion criteria:

1. Age15-55 years

2. Chronic Abnormal uterine bleeding

Exclusion criteria

1. Vaginal bleeding caused by pregnancy and pregnancy related factor

2. Vaginal bleeding caused by vaginitis

3. Vaginal bleeding caused by cervical diseases

4. Vaginal bleeding after menopause

5. Unscheduled bleeding on progestin \pm estrogen gonadal steroids like birth control pills, injections, hormonal intrauterine contraceptive device (IUCD) and non hormonal IUCD's

6. AUB in women, on drugs which are affecting ovulation

The relevant clinical data was collected inclusive of the age, clinical symptoms, associated gynaecological complaints, type of bleeding pattern, any medical disease, and previous hormonal or operative treatment, physical examination, detailed gynaecological examination inclusive of per speculum examination and per vaginal examination. Bleeding pattern was defined by following FIGO 2018 criteria's. $^{5}$

1. Frequency - amenorrhoea for duration of 90 days, cycle length $>38$ days (infrequent) or $<24$ days (frequent).

2. Duration - normal: $\leq 8$ days; prolonged: $>8$ days.
3. Regularity - normal or regular (shortest to longest variation $\leq 7-9$ days); irregular ( $\geq 8-10$ days).

4. Volume - only patient determined - light, normal and heavy; heavy (HMB) - bleeding volume sufficient to interfere with the woman's quality of life.

5. Intermenstrual bleeding - bleeding between cyclically regular onset of menses, either random or cyclic.

Reports of all relevant investigations like haemogram, coagulation profile, hormonal analysis (TSH, prolactin, LH, FSH, DHEAS, fasting insulin, AMH), ultrasound report and endometrial biopsy were noted down. After completion of study, data was entered in Microsoft excel sheet and analysed. Data was described in frequencies and percentages Results

Total 116 women meeting the inclusion and exclusion criteria were enrolled in the study. Prevalence of AUB was highest in the late reproductive age group (30-39 years) age group and perimenopausal (40-49 years), as shown in table 1. According to PALM-COIEN classification system of FIGO prevalence of AUB in women more than 50 years was very low i.e. $5.1 \%$. Non structural causes $(67.4 \%)$ were more common than structural causes (32.6\%). Overall AUB-O was the most common diagnosis found in 55.8\% women followed by AUB - L in 15.4\%, AUB-P in 4.06\%, AUB- A in $7.3 \%$, AUB-M in $5.6 \%$, AUB-C in $0.8 \%$, AUB-E in $4.06 \%$ and AUB-N in $7.7 \%$ (table 2).

\begin{tabular}{lll}
\multicolumn{2}{l}{ Table 1: Age wise distribution of AUB } & \\
\hline Age(years) & $\mathbf{N}=\mathbf{1 1 6}$ & Percentage $\%$ \\
\hline$<19$ & 13 & 11.2 \\
$20-29$ & 23 & 19.8 \\
$30-39$ & 37 & 31.8 \\
$40-49$ & 37 & 31.8 \\
$>50$ & 6 & 5.1 \\
\hline
\end{tabular}

\begin{tabular}{lll}
\multicolumn{4}{l}{ Table 2: Classification of AUB according to PALM-COIEN system } \\
\hline AUB Classification & $\mathbf{N}=\mathbf{1 2 3}$ & Percentages (\%) \\
\hline AUB-P & 5 & 4.06 \\
AUB-A & 9 & 7.3 \\
AUB-L & 23 & 18.6 \\
AUB-M & 3 & 2.4 \\
AUB-C & 1 & 0.8 \\
AUB-0 & 68 & 55.2 \\
AUB-I & Excluded & - \\
AUB-E & 5 & 4.06 \\
AUB-N & 9 & 7.7 \\
\hline
\end{tabular}

Some patients have more than one cause of AUB, so total number of categories is more than number of patients.

On looking at age distribution of various causes of AUB (table 3), all cases (100\%) were due to OD in adolescent age group ( $<19$ years). In early reproductive age group (20-29 years), most common cause was OD $(91.4 \%)$ followed by coagulopathy $(4.3 \%)$ and polyps $(4.3 \%)$. In late reproductive age, almost half of cases were due to OD $(51.3 \%)$ followed 
The New Indian Journal of OBGYN. 2021 (July-December);8(1)

\begin{tabular}{|c|c|c|c|c|c|c|c|c|c|}
\hline Age & $\begin{array}{l}\text { AUB-P } \\
\%(n=5)\end{array}$ & $\begin{array}{l}\text { AUB-A } \\
\%(n=9)\end{array}$ & $\begin{array}{l}\text { AUB-L } \\
\%(n)\end{array}$ & $\begin{array}{l}\text { AUB-M } \\
\%(n)\end{array}$ & $\begin{array}{l}\text { AUB-C } \\
\%(n)\end{array}$ & $\begin{array}{l}\text { AUB-O } \\
\%(n)\end{array}$ & $\begin{array}{l}\text { AUB-E } \\
\%(n)\end{array}$ & $\begin{array}{l}\text { AUB-N } \\
\%(n)\end{array}$ & Total \\
\hline$<19$ & - & - & - & - & - & $100(13)$ & - & - & 13 \\
\hline $20-29$ & $4.3(1)$ & - & - & - & $4.3(1)$ & $91.4(21)$ & - & - & 23 \\
\hline $30-39$ & $2.7(1)$ & $13.5(5)$ & $24.3(9)$ & - & - & $51.3(19)$ & $10.8(4)$ & $2.7(1)$ & 37 \\
\hline $40-49$ & $8.7(3)$ & $10.8(4)$ & $35.1(13)$ & $5.4(2)$ & - & $40.5(15)$ & $2.7(1)$ & $10.8(4)$ & 37 \\
\hline$>50$ & - & - & $16.6(1)$ & $16.6(1)$ & - & - & - & $66.6(4)$ & 6 \\
\hline
\end{tabular}

by leiomyoma (24.3\%) and adenomyosis (13.5\%). In perimenopausal also, OD (40.5\%) accounted for majority of cases, followed by leiomyoma (35.1\%), adenomyosis $(10.8 \%)$ and myometrial hypertrophy $(10.8 \%)$. In women more than 50 years majority of cases were due to AUB-N (66.6\%), 1 case was due to leiomyoma and another due to endometrial hyperplasia. All cases of AUB-N were due to myometrial hypertrophy. Overall, OD was commonest diagnosis of abnormal uterine bleeding among all the age groups.

Table 4: Different causes of AUB - 0

\begin{tabular}{llllll}
\hline $\begin{array}{l}\text { Age } \\
\text { (years) }\end{array}$ & $\begin{array}{l}\text { Thyroid disorders } \\
\text { No }\end{array}$ & $\begin{array}{l}\text { Hyper prolactinemia } \\
\text { No }\end{array}$ & $\begin{array}{l}\text { PCOS } \\
\text { No }\end{array}$ & $\begin{array}{l}\text { Anovulatory } \\
\text { No }\end{array}$ & $\begin{array}{l}\text { Others } \\
\text { No }\end{array}$ \\
\hline$<19$ & 2 & 1 & 5 & 5 & - \\
$20-29$ & 3 & 1 & 13 & 5 & 1 \\
$30-39$ & 12 & 1 & 1 & 3 & - \\
$40-49$ & 3 & - & - & 10 & 2 \\
$>50$ & - & - & - & - & - \\
\hline Total & $29.4 \%(20)$ & $4.4 \%(3)$ & $27.9 \%(19)$ & $33.8 \%(23)$ & $4.4 \%(3)$ \\
\hline
\end{tabular}

Among different causes of AUB-O (table 4), 33.8\% were anovulatory and mostly in age group of 40-49 years. Next common cause was thyroid disorders reported in $29.4 \%$ women, most commonly in age group of 30-39 years, followed by polycystic ovarian syndrome (PCOS) in $27.9 \%$. Most common age of presentation of PCOS was 20-29 years.

\begin{tabular}{lllllll}
\multicolumn{6}{l}{ Table 5: The bleeding patterns of women with AUB-O, AUB-P, AUB-L, AUB-A, AUB-E and AUB-M } \\
\hline $\begin{array}{l}\text { Type of bleeding } \\
\text { pattern }\end{array}$ & $\begin{array}{l}\text { AUB-O } \\
\%(\mathbf{n}=\mathbf{6 8})\end{array}$ & $\begin{array}{l}\text { AUB-P } \\
\mathbf{\%}(\mathbf{n}=\mathbf{5})\end{array}$ & $\begin{array}{l}\text { AUB }-\mathbf{L} \\
\mathbf{\%}(\mathbf{n}=\mathbf{2 3})\end{array}$ & $\begin{array}{l}\text { AUB }-\mathbf{A} \\
\mathbf{\%}(\mathbf{n}=\mathbf{9})\end{array}$ & $\begin{array}{l}\text { AUB-E } \\
\mathbf{\%}(\mathbf{n}=\mathbf{5})\end{array}$ & $\begin{array}{l}\text { AUB-M } \\
\mathbf{\%}(\mathbf{n}=\mathbf{3})\end{array}$ \\
\hline Amenorrhoea & $1.4(1)$ & - & - & - & - & - \\
Infrequent & $33.8(23)$ & - & - & - & - & - \\
Frequent & $14.7(10)$ & - & $13.0(3)$ & $11.1(1)$ & $20(1)$ & $33.3(1)$ \\
Prolonged & $4.4(3)$ & $20(1)$ & $34.7(8)$ & $11.1(3)$ & & \\
Irregular & $44.1(30)$ & $20(1)$ & $8.6(2)$ & $11.1(1)$ & $40(2)$ & $33.3(1)$ \\
Scanty & $11.7(8)$ & - & - & - & - & - \\
Heavy & $27.9(19)$ & $40(2)$ & $86.9(20)$ & $66.7(6)$ & $80(4)$ & $33.3(1)$ \\
Inter menstrual bleeding & $1.4(1)$ & $20(1)$ & - & - & - & - \\
\hline
\end{tabular}
OD, result from anovulation, and $10 \%$ of cases occur with ovulatory cycles. ${ }^{12}$ The reason behind this irregular bleeding is due to dysfunction of hypothalamic pituitary (HPO) axis. Failure of ovulation leads to absence of corpus luteum formation and no secretion of progesterone, causing unopposed estrogen effect on endometrium. Estrogen causes unopposed endometrial proliferation manifesting as breakthrough bleeding. ${ }^{8}$ The major factors affecting HPO axis are PCOS,

As shown in table 5, patients with AUB-O presented with irregular cycles (44.1\%), infrequent cycles (33.8\%) and less commonly HMB (27.9\%) and frequent cycle (14.7\%). In AUB-L, most common bleeding pattern was HMB (66.7\%), followed by prolonged cycle (34.7\%). In AUB-A, most common bleeding pattern was HMB $(66.7 \%)$, followed by frequent $(11.1 \%)$, prolonged $(11.1 \%)$ and irregular pattern (11.1\%). In AUB-P, common bleeding pattern was HMB (40\%), followed by prolonged (20\%), irregular $(20 \%)$ and intermenstrual bleeding (20\%). thyroid disorders and hyperprolactinemia, other factors can be obesity, weight loss, anorexia, mental stress, extreme exercise. ${ }^{13}$ In our study, all cases of AUB in adolescent age group and $90 \%$ of cases in early reproductive age women were due to AUB-O. Irregular cycles (44.1\%) and infrequent cycles $(33.8 \%)$ were the most common bleeding patterns observed with AUB-O similar to observation in other studies ${ }^{8-10}$. The drugs known or suspected to interfere with ovulation are now no longer included in AUB-O. They are now categorised in AUB-I. ${ }^{5}$ 
Next second common cause was AUB-L with the prevalence of $18.6 \%$. Previous studies had shown that prevalence of AUB - L can vary between $9-30 \%$. $8,14,15$ Fibroids are the most common pelvic tumours, and 1.7-2.6 times more common in black women than white women. ${ }^{14}$ Prevalence of AUB-L increases with age i.e. $24.3 \%$ in age group 30-39 years and $35.1 \%$ in $40-49$ years, as reported earlier also. ${ }^{8,14}$ AUB can be associated with fibroids but may not be the sole cause of AUB. In more than $50 \%$ of patients uterine fibroids are asymptomatic. ${ }^{16}$ Symptoms of AUB depends on the location and size of fibroids. ${ }^{11}$ AUB in fibroid can be due to increase in endometrial surface area, presence of engorged vasculature in perimyoma environment. ${ }^{17}$ Also, there could be some field changes within uterine cavity which have an impact upon endometrial receptivity and implantation. ${ }^{18}$ Bleeding pattern mostly associated with AUB-L was HMB (86.9\%) and prolonged cycles (34.7\%) in our study. Sun et al reported HMB in $51 \%$ and prolonged cycles in $44 \%{ }^{8}$

Uterine adenomyosis had varied prevalence in different population. Prevalence in women undergoing assisted reproductive technology is $20-25 \%,{ }^{19}$ with endometriosis it is $20-80 \%,{ }^{20}$ and $20.9 \%$ in general population, undergoing ultrasound ${ }^{21}$ and $10-35 \%$ in histological specimens after hysterectomy. ${ }^{22}$ Adenomyosis is most commonly found in fourth decade but now increasingly diagnosed in young women with infertility, dysmenorrhoea or AUB. This is because of increase in more stringent ultrasound and MRI criteria's for diagnosis. ${ }^{23}$ Prevalence of AUB-A in late reproductive age was $13.5 \%$ and in perimenopausal it was $10.8 \%$. Although gold standard for making diagnosis of AUB-A is histopathological, but now FIGO suggests that use of the "transvaginal ultrasonography (TVUS) based morphological uterus sonographic assessment (MUSA) group criteria" for diagnosis of adenomyosis. These are the graphical depictions of the eight TVUS criteria, which include - asymmetrical myometrial thickening ; myometrial cysts ; hyperechoic islands ; fan shaped shadowing; echogenic subendometrial lines and buds; translesional vascularity; irregular junctional zone; and an interrupted junctional zone. The presence of two or more of these criteria is highly associated with a diagnosis of adenomyosis ${ }^{5}$. The sensitivity of TVUS to detect adenomyosis ranges from $65 \%$ to $81 \%$, and specificity ranges from $65 \%$ to $100 \% .{ }^{28}$ Adenomyosis mostly presents with $\mathrm{HMB}^{23,24}$ In our study also main bleeding pattern was HMB i.e. $66.7 \%$, followed equally by frequent, prolonged and irregular cycles in $11.1 \%$ in each category. Cause of abnormal bleeding in adenomyosis may be associated with increased uterine volume causing increased uterine surface area and possibly affecting normal myometrial contractility. ${ }^{11,25}$

Uterine polyps are localised hyperplastic overgrowths of endometrial glands with prevalence of $7.8-34.9 \%{ }^{26} \mathrm{We}$ found prevalence of $4.08 \%$. Most common symptom associated with polyp is abnormal bleeding i.e. occurring in approximately $68 \%$ of both pre and postmenopausal women. ${ }^{27}$ Risk factors are age, tamoxifen use, obesity, increased level of estrogen, Lynch syndrome. ${ }^{28}$ Bleeding may be due to stromal congestion within the polyp leading to venous stasis and apical necrosis. ${ }^{29}$ Endometrial polyps can be accurately diagnosed using transvaginal ultrasound (TVUS) (sensitivity, 91\%; specificity, 90\%), saline infusion sonohysterography (SIS) (sensitivity, 95\%; specificity, $92 \%$ ), diagnostic hysteroscopy (sensitivity, 90\%; specificity, 93\%), and hysterosalpingography (sensitivity, 98\%; specificity, 35\%). ${ }^{27}$ Polyps may coexist with endometrial intraepithelial neoplasia (EIN) in approximately 1.7$5.42 \%,{ }^{30}$ and endometrial polyps may be mistaken for prolapsing leiomyoma. ${ }^{30}$ Submucosal fibroids can be differentiated from polyp by the fact that they typically have an overlying layer of the echogenic endometrium, which helps in confirming their subendometrial location. ${ }^{31}$

AUB-M accounts for $1.9-5 \%{ }^{8,15}$ We found AUB-M as cause of AUB in $2.4 \%$. In all cases histopathological report was suggestive of endometrial hyperplasia without atypia. Endometrial biopsy was done by pipelle device in our study. The sensitivity for endometrial cancer by endometrial sampling using the pipelle device in premenopausal women is $91 \%$, and the sensitivity for diagnosis of EIN (subtype: atypical endometrial hyperplasia) is $81 \% .{ }^{32}$ The risk factors for endometrial intraepithelial neoplasia (EIN) and malignancy can be due to unopposed estrogen with an intact uterus, obesity, diabetes mellitus, hypertension, nulliparity, tamoxifen use. ${ }^{33,}{ }^{34}$ Lifetime risk of developing endometrial cancer in women is $2.8 \%$ but fortunately, $70 \%$ of cases are found at an early stage because $75 \%-90 \%$ women with malignancy presents with AUB. ${ }^{33} \mathrm{HMB}$ is reported in all patients with frequent and irregular cycle in $33.3 \%$ of women. Yelmaz et al also found menorrhagia as most common symptom. ${ }^{35}$

AUB- E accounts for 2.6- $15 \%$ of cases, we found prevalence of $4.0 \%$. Endometrial disorders were mainly because of primary dysfunction of local endometrial 
The New Indian Journal of OBGYN. 2021 (July-December);8(1)

hemostasis, likely deficiencies in vasoconstriction (endothelin-1, prostaglandin F2a) and more production of plasminogen leading to increased lysis of clot. ${ }^{36}$ Other cause may be due to Chlamydia trachomatis or Ureaplasma infections leading to endometritis. ${ }^{37}$ Women presents with predictable and cyclic menses suggestive of normal ovulation but have HMB. ${ }^{38}$ We founded $80 \%$ of them have $\mathrm{HMB}$, others have irregular and frequent cycle.

AUB-C has varied prevalence of $1.04-40 \%{ }^{8,11}$ It can be inherited (factor VIII, IX, VII, XI, and platelet disorders) or acquired. ${ }^{38}$ Commonest cause of AUB-C is Von Willebrand disease (vWF), identifiable in $5 \%$ to $24 \%$ of women with HMB. ${ }^{39}$ AUB-C should be considered in any women presenting with $\mathrm{HMB}$ and prolonged menses since puberty. ${ }^{38}$ We had found only 1 case with AUB-C, 21 yr old unmarried, nulligravid girl presented to us with HMB since puberty there was no history of frequent bruising, epistaxis, gum bleeding or family history of bleeding problem. No history of surgical site bleeding or bleeding associated with dental work. On investigating her, found to have increased APTT. She came out as vWF deficiency.

AUB-N "not otherwise classified" are group of entities, which are poorly defined or inadequately examined and are generally rare. They include arteriovenous malformation, myometrial hypertrophy, and uterine isthmocele secondary to caesarean delivery scar defect. Imaging such as TVUS and MRI may be helpful. ${ }^{5}$ In our study all cases of AUB-N were of myometrial hypertrophy.

This study investigates all causes of AUB, excluding only AUB-I, and provides the data for Indian population. We analysed all types of AUB individually with regards to prevalence, age, cause and bleeding pattern. Limitation of our study is hysteroscopy which wasn't done in any of the case included in study. Structural cause differentiation was only on the basis of clinical findings and ultrasound report. Another limitation is small sample size but this could provide preliminary data for future well planned study with larger sample size.

Clinical significance: Even In the era of high fidelity imaging technology, detailed history taking and ultrasonography with simple Doppler studies are important diagnostic modality to rule out various structural and non structural causes of AUB, with high sensitivity and specificity. Even important diagnostic dilemma, i.e. adenomyosis can also be diagnosed by ultrasonography using MUSA criteria, if expertise is available.

\section{Conclusion}

AUB is common symptom of gynaecological condition. Non structural causes are more common than structural causes and ovulatory dysfunction is the commonest non structural cause, accounting for more than half of cases among AUB. Merely history taking along with special emphasis on age and bleeding pattern with simple gynaecological examination can help in making diagnosis in outpatient department.

Acknowledgements: I thank all the women who consented to participate in the study as well as the staff at the centre for their assistance with study enrolment.

\section{Conflict of interest: None. Disclaimer: Nil.}

\section{References}

1. Munro MG, Critchley HO, Fraser IS. The flexible FIGO classification concept for underlying causes of abnormal uterine bleeding. Semin Reprod Med. 2011; 29: 391- 9

2. Padubidri VG, Daftary SN. Shaw's Textbook of Gynecology. 16 th ed. USA: Elsevier Health Sciences; 2015: 335-48.

3. Liu Z, Doan QV, Blumenthal P, et al. A systematic review evaluating health-related quality of life, work impairment, and health care costs and utilization in abnormal uterine bleeding. Value Health. 2007;10: 173-82.

4. Kazemijaliseh H, Ramezani Tehrani F, Behboudi Gandevani S, et al. A Population-based study of the prevalence of abnormal uterine bleeding and its related factors among Iranian reproductive-age women: an updated data. Arch Iran Med. 2017; 20: 558 - 63.

5. Munro MG, Critchley HO, Fraser IS. The two FIGO systems for normal and abnormal uterine bleeding symptoms and classification of causes of abnormal uterine bleeding in the reproductive years: 2018 revisions. Int J Gynecol Obstet. 2018; 143: 393 - 408.

6. Singh N, Faruqi M, Pradeep Y. Clinico-epidemiological profile of abnormal uterine bleeding in reproductive womens: a cross sectional study. Int J Reprod Contracept Obstet Gynecol. 2019; 8: 4395-9.

7. Palwade JM, Borole CS. A study of causes of abnormal uterine bleeding with res classification in the patients at perimenopausal age. Med FIGO Pulse - Int Med J. 2016; 3: 987-91.

8. Sun Y, Wang Y, Mao L, Wen J, Bai W. Prevalence of abnormal uterine bleeding according to new 
International Federation of Gynecology and Obstetrics classification in Chinese women of reproductive age: A crosssectional study. Medicine (Baltimore) 97. 2018: e11457.

9. Hauk L. American College of Obstetricians and Gynecologists ACOG releases guidelines on management of abnormal uterine bleeding associated with ovulatorydysfunction. Am Fam Physician 2014; 89: $987-8$.

10. Committee on Practice Bulletins - Gynecology Practice bulletin no. 136: Management of abnormal uterine bleeding associated with ovulatory dysfunction. Obstet Gynecol. 2013; 122: 176-85.

11. Whitaker L, Critchley HOD. Abnormal Uterine Bleeding. Best Practice \& Research Clinical Obstetrics \& Gynaecology. 2016 Jul; 34: 54-65

12. Rosen P, Marx JA, Hockberger RS, Walls M, Adams G. Rosen's Emergency Medicine: Concepts and Clinical Practice. 7th ed. Philadelphia: Mosby (Elsevier); 2009.

13. Thurston L, Abbara A, Dhillo WS. Investigation and management of subfertility. J Clin Pathol. 2019;72 (9):579-587. doi:10.1136/jclinpath-2018-205579

14. Yu O, Scholes D, Schulze-Rath R, et al. A US population-based study of uterine fibroid diagnosis incidence, trends, and prevalence: 2005 through 2014. Am J Obstet Gynecol 2018; 219: 591.e1-8.

15. Singh K, Agarwal C, Pujani $M$, et al. A Clinicopathological Correlation of International Federation of Gynecology and Obstetrics's PALMCOEIN Classification of Abnormal Uterine Bleeding: Indian Scenario. J Midlife Health. 2019; 10(3):147-52.

16. Divakar H. Asymptomatic uterine fibroids. Best Pract Res Clin Obstet Gynaecol. 2008; 22(4): 643-54.

17. Munro MG. Classification of menstrual bleeding disorders. Rev Endocr Metab Disord. 2012;13(4): 225-34.

18. Sinclair DC, Mastroyannis A, Taylor HS. Leiomyoma simultaneously impair endometrial BMP-2-mediated decidualization and anticoagulant expression through secretion of TGF-beta3. J Clin Endocrinol Metab. 2011; 96: 412-21.

19. Puente JM, Fabris A, Patel J, et al. Adenomyosis in infertile women: prevalence and the role of $3 \mathrm{D}$ ultrasound as a marker of severity of the disease. Reprod Biol Endocrinol. 2016; 14(1): 60.

20. Di Donato N, Montanari G, Benfenati A, et al. Prevalence of adenomyosis in women undergoing surgery for endometriosis. Eur J Obstet Gynecol Reprod Biol. 2014; 181: 289-93.

21. Eisenberg VH, Arbib N, Schiff E, et al. Sonographic Signs of Adenomyosis Are Prevalent in Women Undergoing Surgery for Endometriosis and May Suggest a Higher Risk of Infertility. Biomed Res Int. 2017; 2017: 8967803.

22. Bergholt T, Eriksen L, Berendt N, et al. Prevalence and risk factors of adenomyosis at hysterectomy. Hum Reprod. 2001; 16(11): 2418-21.

23. Vannuccini S, Petraglia F. Recent advances in understanding and managing adenomyosis. F1000Res. 2019; 8: F1000 Faculty Rev-283.

24. Gupta S, Goel G, Agrawal S, et al. Clinical and ultrasonological features of adenomyosis and its histopathological correlation. Int $\mathrm{J}$ Reprod Contracept Obstet Gynecol. 2016; 5:10.

25. Aguilar HN, Mitchell BF. Physiological pathways and molecular mechanisms regulating uterine contractility. Hum Reprod Update. 2010;16(6): 725-44.

26. Lee SC, Kaunitz AM, Sanchez-Ramos L, Rhatigan RM. The oncogenic potential of endometrial polyps: a systematic review and meta-analysis. Obstet Gynecol. 2010;116(5):1197-205.

27. Salim S, Won H, Nesbitt-Hawes E, et al. Diagnosis and management of endometrial polyps: a critical review of the literature. J Minim Invasive Gynecol. 2011; 18(5): $569-81$.

28. Nijkang NP, Anderson L, Markham R, Manconi F. Endometrial polyps: Pathogenesis, sequelae and treatment. SAGE Open Med. 2019 May 2; 7: 2050312119848247.

29. Jakab A, Ovari L, Juhasz B, et al. Detection of feeding artery improves the ultrasound diagnosis of endometrial polyps in asymptomatic patients. Eur J Obstet Gynecol Reprod Biol. 2005; 119(1): 103-7.

30. Spiewankiewicz B, Stelmachow J, Sawicki W, Cendrowski K, Ku_zlik R. Hysteroscopy in cases of cervical polyps. Eur J Gynaecol. 2003; 24(1): 67-9.

31. Murase E, Siegelman ES, Outwater EK, Perez-Jaffe LA, Tureck RW. Uterine leiomyomas: histopathologic features, MR imaging findings, differential diagnosis, and treatment. Radiographics.1999;19(5):1179-97.

32. Dijkhuizen FP, Mol BW, Brolmann HA, Heintz AP. The accuracy of endometrial sampling in the diagnosis of patients with endometrial carcinoma and hyperplasia: a meta-analysis. Cancer. 2000; 89(8):1765-72. 
33. American Cancer Society. Key statistics for endometrial cancer. Available from: http://www.cancer.org/ cancer/endometrial-cancer /about/ keystatistics. html. Accessed January 5, 2018.

34. Practice Bulletin No 149. Endometrial cancer. Obstet Gynecol. 2015;125(4):1006-26.

35. Yilmaz Z, Yilmaz EA, Cakmak B, Gultekin IB, Karsli MF, Cekmez Y, et al. Correlation of bleeding pattern with endometrial histopathologic results in perimenopausal women with abnormal uterine bleeding. International Journal of Reproduction, Contraception, Obstetrics and Gynecology. 2017: 4(3): 547-50.

36. Nordengren J, Pilka R, Noskova V, et al. Differential localization and expression of urokinase plasminogen activator ( $\mathrm{UPA}$ ), its receptor ( $\mathrm{UPAR}$ ), and its inhibitor (PAI-1) mRNA protein in endometrial tissue during the menstrual cycle. Mol Hum Reprod. 2004;10(9):655-63.
37. Committee on Practice Bulletinse Gynecology. Practice bulletin no. 128: diagnosis of abnormal uterine bleeding in reproductive aged women. Obstet Gynecol. 2012;120(1):197-206.

38. Marnach ML, Laughlin-Tommaso SK. Evaluation and Management of Abnormal Uterine Bleeding. Mayo Clin Proc. 2019; 94(2): 326-35.

39. Shankar M, Lee CA, Sabin CA, Economides DL, Kadir RA. Von Willebrand disease in women with menorrhagia: a systematic review. Br J Obstet Gynaecol. 2004;111(7):734-40.

Preeti Bala Singh ${ }^{1}$, Roli Purwar ${ }^{2}$, Ratna Priya Mall ${ }^{3}$

${ }^{1}$ Assistant professor, Department of Obstetrics and Gynaecology, AlIMS, Gorakhpur, Uttar Pradesh, India;

${ }^{2}$ Senior Resident, Department of Obstetrics and Gynaecology, AIIMS, Gorakhpur, Uttar Pradesh, India;

${ }^{3}$ Junior resident, Department of Obstetrics and Gynaecology, AlIMS, Gorakhpur, Uttar Pradesh, India. 